\title{
Study on Static and Dynamic Characteristics Analysis of Long Span Steel Concrete Composite Beam Cable-stayed Bridge
}

\author{
Wusheng Tian ${ }^{1, a}$, Bin Liang ${ }^{1, b}$, Xingliang Jin ${ }^{1, c}$ \\ ${ }^{1}$ Civil Engineering School, Henan University of Science and Technology, Luoyang 471023, China

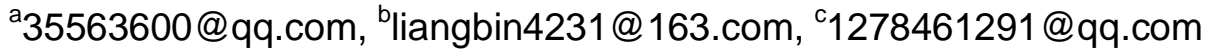

Keywords: large span; steel concrete composite beam; static and dynamic characteristics; finite element;

\begin{abstract}
The Gangjiang No.2 Bridge is studied as the research object. The three-dimensional finite element bridge model is established with ANSYS 15.0 about static and dynamic characteristics of the bridge. The main girder and the main tower stress have enough safety storage, which can meet the specification requirements. The results show that the first order of the bridge vibration period is $4.2158 \mathrm{~s}$, which is small to the general cable-stayed bridge. But the girder vertical bending, distortion occurs earlier than the steel - concrete cable-stayed bridge with high integral rigidity. It is sensitive to wind load, seismic force.
\end{abstract}

\section{Introduction}

Steel concrete composite beam cable-stayed bridge is a structure composed of steel main beam and concrete slab, and the main girder is connected with the bridge deck. Steel-concrete composite girder cable-stayed bridge structure is complex, especially the use of steel-concrete composite beam structure, make the stress more complex of this type of cable-stayed bridge[1]. Due to reduce the dead weight of beams, the distribution of internal force of the whole bridge is complicated, need to set the weight of small side span beam, prevent side span girder in the cable under the action of the arch is too large, resulting in concrete bridge decks subjected to tension stress[2]. With the increase of span, the flexibility of the whole bridge becomes larger, and the steel concrete composite girder cable-stayed bridge becomes sensitive to dynamic response.

With the increase of the span of the bridge, the steel concrete composite beam cable-stayed bridge will have wider application background[3-4]. Therefore, it is necessary to carry on the numerical simulation analysis of the steel concrete composite beam cable-stayed bridge, and analyze its static and dynamic characteristics. Provide the technical reference for future design and construction of this type of bridge, make better optimization of the bridge.

\section{Project Profile}

Gangjiang No.2 Bridge with $2529 \mathrm{~m}$ span is a cable\& stayed bridge with twin towers, twin cable planes and semi-floating superposed beams. The bridge span is $54+114+400+114+54 \mathrm{~m}$. The general arrangement is shown in Figure 1. The standard section of the main beam is shown in Figure 2. Double tower is a reinforced concrete structure, height of $124 \mathrm{~m}$ above the deck tower height of $100 \mathrm{~m}$, the main tower of effective height and span ratio of 0.25 , the four corners of rectangular section is circular, the tower cross bridge to the curve line. 


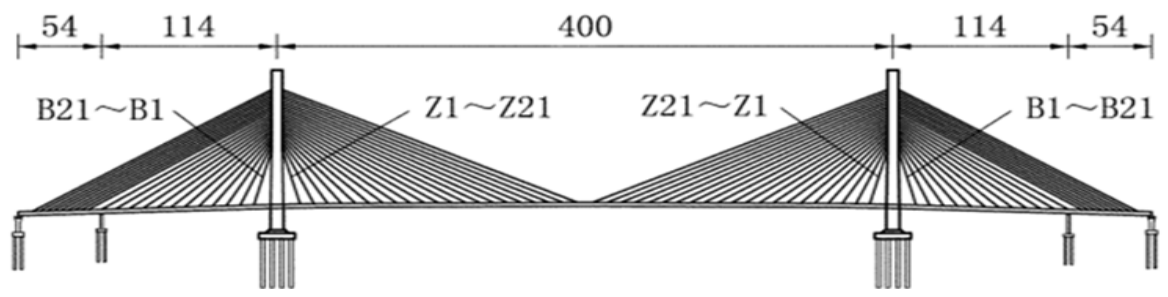

Fig.1 Bridge span arrangement

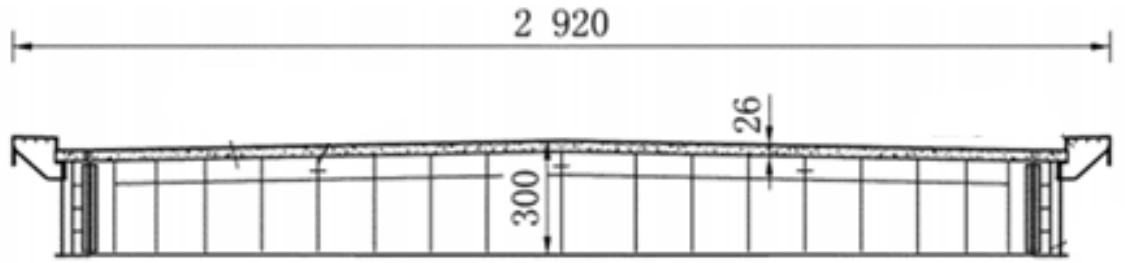

Fig.2 Standard cross section of main beam

\section{Finite element model}

Using finite element analysis software ANSYS to establish beam finite element model for Gangjiang No.2 steel-concrete composite twin towers cable-stayed bridge, considering the real simulation of steel-concrete composite beam, the whole bridge is modeled by 3D solid model. In the ANSYS finite element software, the $\mathrm{X}$ axis is transverse to the bridge, the $\mathrm{Y}$ axis is in the vertical direction, and the $\mathrm{Z}$ axis is the direction of the bridge. The finite element model of the whole bridge and main tower is shown in Figure 3 and Figure 4.

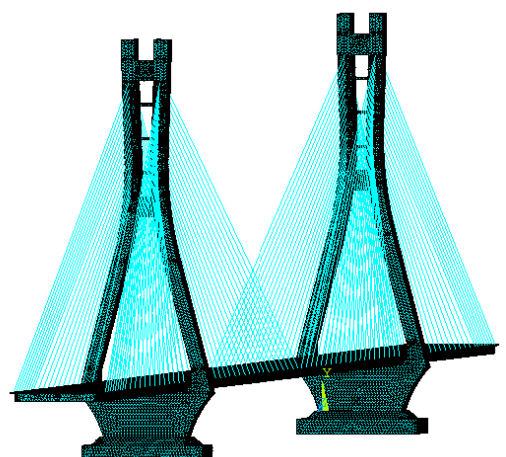

Fig.3 3-D finite element model

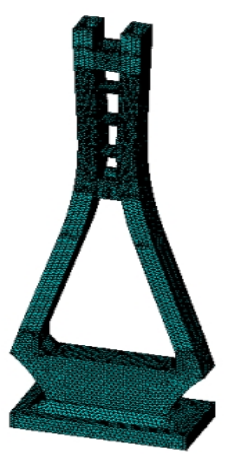

Fig.4 3-D finite element model of main tower

\section{Bridge static analysis}

Analysis of force and displacement of main girder. Based on the space finite element model of Ganjiang No.2 bridge in normal state and limit state of bearing capacity of the combination of internal forces. The deflection of steel concrete composite beam under two kinds of internal force combination is shown in figure 9. The stress analysis of concrete bridge deck and steel girder is carried out. The stress is shown in Figure 10. 


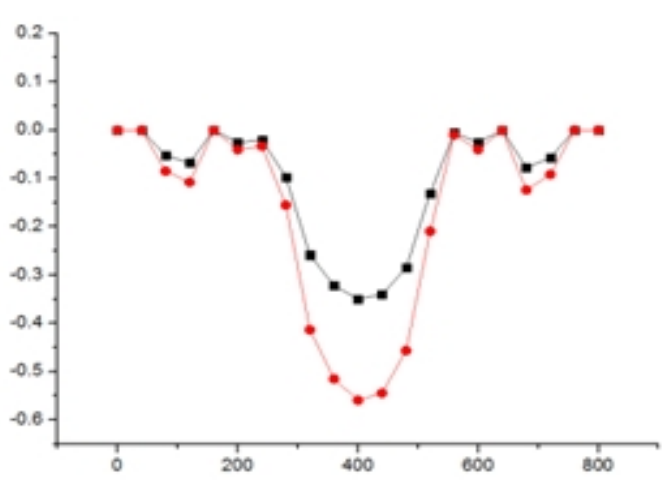

Fig.5 Down deflection curve

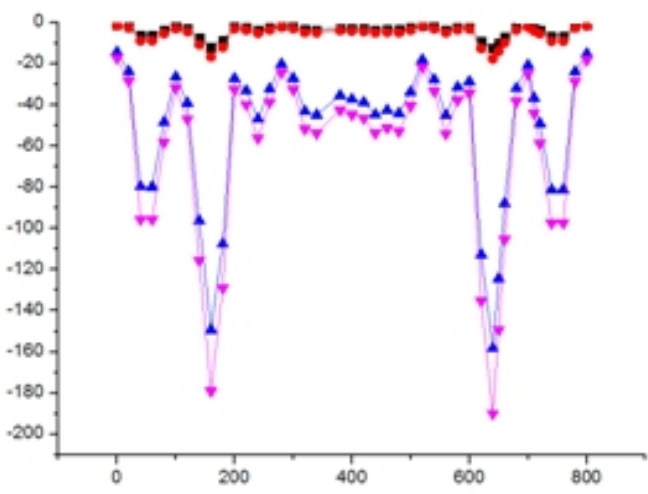

Fig.6 Stress curve

It can be seen from Figure 9, the steel - concrete composite beams in ultimate limit state under operating conditions, the maximum upward deflection is $0.08 \mathrm{~m}$, the maximum downward deflection value is $0.56 \mathrm{~m}$ and the maximum deflection amplitude $=0.08+0.56=0.64<\mathrm{L} / 400=1.0 \mathrm{~m}$, meeting the requirements of specification.

It can be seen from Figure 10, under the combination of the most unfavorable load effect of the concrete bridge deck under the two conditions, the maximum compressive stress is $17.8 \mathrm{MPa}$, which is less than the design value of C60 concrete compressive strength, meeting the requirements of specification.

Analysis of displacement of main tower. Under the combination of two kinds of working conditions, the internal force combination of the bearing capacity limit state and the normal working condition internal force combination, The displacement curve of the bridge is shown in the figure.

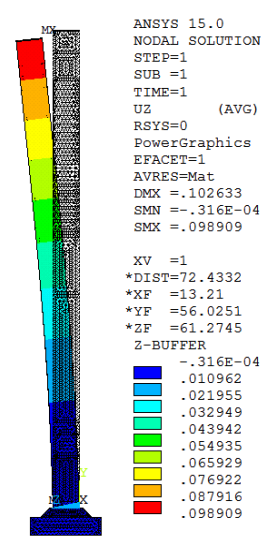

Fig.7 Displacement under the first condition

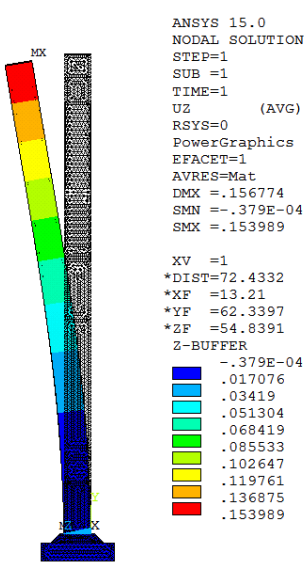

Fig.8 Displacement under the second condition

It can be seen from Figure 9, under normal operation condition, the maximum displacement of the bridge is $0.0989 \mathrm{~m}$, under the combined condition of ultimate bearing capacity, The maximum displacement of the bridge is $0.153989 \mathrm{~m}$. Maximum displacement occurs at the top of the tower.

\section{Bridge dynamic analysis.}

The behavior of natural oscillation under completion state were calculated and analyzed. As shown in the table, it used Block Lanczos method to calculate and analyze the Ganjiang No.2 bridge of the first five natural frequencies. 
Tab.1 The first five natural frequencies

\begin{tabular}{|c|c|c|c|}
\hline Order & Frequenc $(\mathrm{Hz})$ & Cycle $(\mathrm{s})$ & Modal characteristics \\
\hline 1 & 0.23720 & 4.2158 & Symmetrical vertical bending of main beam \\
\hline 2 & 0.39202 & 2.5509 & Anti symmetrical vertical bending of main beam \\
\hline 3 & 0.64806 & 1.5431 & Symmetrical vertical bending of main beam \\
\hline 4 & 0.73754 & 1.3559 & Longitudinal floatin of main bridge \\
\hline 5 & 0.78522 & 1.2735 & Axial torsion of main girder bridge \\
\hline
\end{tabular}

It can be seen from table 1, Vibration period is $4.2158 \mathrm{~s}$ in the first order, the main characteristic of vibration mode is Symmetrical vertical bending of main beam. The results show that the whole bridge is sensitive to the vertical seismic wave and the impact vibration of the vertical vehicle. The 4 order vibration mode is the longitudinal drift of the whole bridge, which means that under the influence of the longitudinal seismic wave, the pier will be subjected to greater stress.

\section{Conclusion}

Using the finite element software ANSYS 15 of the Twin Towers double cable plane steel concrete composite beams to establish three-dimensional finite element model of cable-stayed bridge, and analyzes its static and dynamic characteristics, obtained some structural characteristics of Gangjing No.2 Bridge. The conclusions are as follows.

Ganjiang No.2 bridge steel-concrete composite girder cable-stayed bridge in the normal state and the bearing force of internal force combination limit state combination of two kinds of load conditions of girder deflection amplitude is $0.64 \mathrm{~m}$. Under normal operation condition, the maximum displacement of the bridge is $0.0989 \mathrm{~m}$, under the combined condition of ultimate bearing capacity, the maximum displacement of the bridge is $0.153989 \mathrm{~m}$. All data can meet the relevant specifications.

The steel-concrete composite beam Twin Towers cable-stayed bridge with double cable planes 1 order vibration period is $4.2518 \mathrm{~s}$, than the average large span cable-stayed bridge 1 order vibration cycle is small, but the laminated beam appeared around the longitudinal axis of torsion beam of cable-stayed bridge, steel - concrete composite beam cable bridge overall stiffness, but is easily affected by the earthquake, the dynamic effect of wind load.

\section{References}

[1] J.J. Qi, L.Z. Jiang, Exeperimental study on seismic behaviors of steel-concrete composite frames, J. Cent.South University. 22 (2015) 4396-4413. (in Chinese)

[2] L.Y. Zhou, Z.W. Yu, G.G. He, A new 3-D element formulation on displacement of steel-concrete composite box beam, J. Cent. South University. 20 (2013) 1354-1360.(in Chinese)

[3] G. L. Dai, B. Yan, Longitudinal forces of continuously welded track on high-speed railway cable-stayed bridge considering impact of adjacent bridge, J. Centsouth University. 18 (2012) 1480-1485. (In Chinese)

[4] Q.K. Liu, S.Z. Qiang, Q. Zhang, Structural Analysis of ear-plate cable and beam anchorage For cable-stayed bridge, J .China Journal of Highway and Transport. 15 (2002) 72-75.(In Chinese) 